\title{
O PAPEL DO MUNICÍPIO DIANTE DO FENÔMENO DO ATO INFRACIONAL: DEMARCAÇÕES SOCIOJURÍDICAS A PARTIR DA LEI DO SINASE.
}

\author{
Claudio Alberto Gabriel Guimarães*
}

Valdira Barros*

\begin{abstract}
RESUMO: O objetivo do presente artigo é analisar o papel desempenhado pelos municípios para enfrentamento do fenômeno do ato infracional a partir das inovações introduzidas pela Lei do SINASE. Baseado em revisão bibliográfica e pesquisa documental, demarca-se a fundamentação teórica e legal do sistema de controle do ato infracional no âmbito do ordenamento jurídico brasileiro. Investiga-se, outrossim, o contexto social de ocorrência e a natureza dos atos infracionais praticados pelos menores, o perfil de tais adolescentes autores de atos infracionais, as medidas de responsabilização previstas no Estatuto da Criança e do Adolescente e, por fim, as inovações introduzidas pela Lei do SINASE quanto aos objetivos das medidas socioeducativas e competências dos municípios no tratamento da problemática do ato infracional.
\end{abstract}

PALAVRAS-CHAVE: PALAVRAS-CHAVE: Fundamentação e legitimação do direito de punir; adolescente infrator; ato infracional; medidas socioeducativas; SINASE

\section{THE ROLE OF THE MUNICIPALITY BEFORE THE PHENOMENON OF THE INFRARED ACT: SOCIO-JURIDICAL DEMARCATIONS FROM THE LAW OF SINASE.}

ABSTRACT: The aim of this article is to analyze the role played by municipalities to face the phenomenon of the infraction act from the innovations introduced by the SINASE Law. Based on a bibliographical review and documentary research, the theoretical and legal basis of the system of control of the infraction act within the scope of the Brazilian legal system is

\footnotetext{
* Promotor de Justiça do Estado do Maranhão. Coordenador Estadual da Associação Brasileira de Professores de Ciências Penais - ABPCP. Sócio Fundador do Instituto Panamericano de Política Criminal. Especialista em Direito, Estado e Sociedade pela Universidade Federal de Santa Catarina. Especialista em Docência Superior pelo Centro Universitário do Maranhão - UNICEUMA. Mestre em Direito Público pela Universidade Federal de Pernambuco. Doutor em Direito Público pela Universidade Federal de Pernambuco, com área de concentração em Direito Penal. Doutor em Direito pela Universidade Federal de Santa Catarina, com área de concentração em Criminologia. Professor Pesquisador do CNPq, UNICEUMA e FACEMA. Professor Adjunto da Universidade Federal do Maranhão. E-mail: calguimaraes@yahoo.com.br

* Advogada, militante do Centro de Defesa dos Direitos da Criança e do Adolescente Pe. Marcos Passerini; Assessora do Centro Cultural e Educacional Mandingueiros do Amanhã. Especialista em Violência Contra Crianças e Adolescentes (LACRI/USP). Mestre e Doutora em Políticas Públicas pelo Programa de PósGraduação em Políticas Públicas da Universidade Federal do Maranhão. Professora da UNICEUMA e Professora Adjunta I da Universidade Estadual do Maranhão. E-mail: valdirabarros@gmail.com
} 
demarcated. It also investigates the social context of occurrence and the nature of the infraction acts committed by the minors, the profile of such adolescents who commit acts of infraction, the measures of accountability foreseen in the Statute of the Child and the Adolescent and, finally, the innovations introduced by the SINASE Law regarding the objectives of socio-educational measures and municipalities' competences in the treatment of the problem of the infraction.

KEYWORDS: Rationale and legitimacy of the right to punish; Juvenile offender; infraction; educational measures; SINASE

\section{Introdução}

O tema da segurança pública e, de maneira correlata da violência perpetrada por adolescentes, tem sido recorrentemente abordado nos meios de comunicação de massa, sem no entanto, implicar uma abordagem aprofundada acerca das políticas e programas desenvolvidos para o enfrentamento do problema.

O Estatuto da Criança e do Adolescente (ECA) denominou ato infracional o ilícito de natureza penal praticado por crianças ou adolescentes, dispondo sobre uma série de medidas de natureza protetiva e socioeducativa aplicáveis aos adolescentes na hipótese de condutas infracionais. Todavia, o ordenamento carecia de uma legislação que regulamentasse o processo de execução destas medidas, lacuna esta que seria suprimida no ano de 2012 com a aprovação da Lei 12.594/2012 que institui o Sistema Nacional de Atendimento Socioeducativo - SINASE.

Este artigo foi construído com o propósito de possibilitar uma reflexão acerca das inovações introduzidas pela chamada Lei do SINASE no tocante à delimitação do papel desempenhado pelos municípios na execução das medidas socioeducativas.

Chama-se a atenção para o fato, relativamente novo, de se inserir cada vez mais os municípios brasileiros em questões afetas à segurança pública ${ }^{1}$.

A partir de revisão bibliográfica e pesquisa documental, iniciamos o texto com uma reflexão sobre os fundamentos teóricos da punição, para em seguida refletirmos sobre as especificidades dos ilícitos praticados por adolescentes, as medidas previstas no ordenamento

\footnotetext{
${ }^{1}$ Sobre o tema, em maior profundidade, Guimarães e Pereira (2014).
} 
brasileiro, e as alterações introduzidas pela Lei 12.594/2012, com destaque para a função dos municípios no processo de responsabilização dos adolescentes autores de ato infracional.

\section{Fundamentos da punição: controle social do adolescente infrator}

Na seara das punições, qualquer que seja o seu âmbito, necessário se faz explicitar o discurso hodierno sobre as razoes pelas quais o castigo, em uma perspectiva formal, deve, ou não, ser utilizado como instrumento para disciplinar a sociedade ${ }^{2}$.

É cada vez mais comum nas discussões acadêmicas que se apresentem argumentos fundamentados na falência da pena de prisão, no abolicionismo ${ }^{3}$ ou minimalismo penais, na profunda crise do sistema penitenciário, entre tantos outros que, em maior ou menor medida, questionam a existência ou, pelo menos, o funcionamento do Sistema de Controle Social formal $^{4}$.

$\mathrm{Na}$ esfera do controle social do adolescente infrator, o tema torna-se ainda mais delicado, vez que o problema a ser enfrentado encontra-se situado em uma área na qual estáse a lidar com pessoas ainda em formação - o que é reconhecido formalmente pela doutrina da inimputabilidade -, não obstante existir um permanente confronto legislativo, objetivando alterar os dispositivos em vigor, para diminuir a idade da responsabilização penal.

Pelo exposto, não é difícil concluir, que em termos de controle social formal, em especial da disciplina do menor infrator, vivemos em uma época de extremismos, passando-se do tratamento não penal da questão para um enfrentamento rigorosamente punitivo da mesma.

Cada vez mais tem se aprofundado o contexto da bipolaridade da questão: de um lado os que se colocam ao lado da vertente humanitária das punições, cuja base é terapêutica, também defendendo modelos consensuais para solução dos conflitos, mormente a Justiça

\footnotetext{
${ }^{2}$ Segundo Muñoz Conde (2005, p. 8;11), "Para regular a convivência entre os homens, estabelecem-se normas vinculantes que devem ser respeitadas pelas pessoas enquanto membros da comunidade. $\mathrm{O}$ acatamento dessas normas é uma condição indispensável para a convivência em sociedade. A ordem jurídica e o Estado não são, por conseguinte, mais que um reflexo ou superestrutura de uma determinada ordem social incapaz, por si mesma, de regular a convivência de um modo organizado e pacífico. Na medida em que a ordem social seja autosuficiente, poderemos prescindir da ordem jurídica e do Estado".

${ }^{3}$ Sobre o assunto, imprescindível a leitura das obras precursoras da discussão: Hulsman (1989);;Hulsman e Celis (1997).

${ }^{4}$ Andrade (2008) sobre o Sistema Penal, explica que: “... o sistema penal, mecanismo de controle social formal (Legislativo- Lei Penal- Polícia- Ministério Público- Judiciário- Prisão- ciências criminais- sistema de segurança pública, etc.) constrói a criminalidade e os criminosos em interação com o controle social informal (famíliaescola - universidade- mídia- religião- moral- mercado de trabalho- hospitais- manicômios), funcionalmente relacionados às estruturas sociais”.
} 
Restaurativa5. No extremo oposto o grupo que se filia a tradicional corrente retributivista, modernizada sob o título de neoretribucionismo, que entende deva ser a punição aplicada como defesa da ordem jurídica e, consequentemente, como defesa da própria existência do Estado. (LEWIS, 2011).

Logo, em maior ou menor medida, as discussões acerca do controle social situam-se nos dois campos teóricos acima delineados, trazendo, entretanto, uma nova denominação para ambos: o realismo de direita - outrora ideologia da defesa social - e o realismo de esquerda vinculado às teorias críticas ou do conflito.

Em tempos de muito confronto teórico, portanto, pensamos ser absolutamente imprescindível, iniciar a discussão respondendo a uma pergunta bastante simples, qual seja: o Direito Penal e, a reboque, todas as instituições do Sistema de Controle Social formal, são ou não necessários para o modelo de Estado Democrático de Direito que se vivencia hoje no Brasil?

Como primeira premissa a ser construída no presente texto, temos que o discurso oriundo dos contratualistas 6 se encontra em pleno vigor, ou seja, a sociedade precisa de instituições formais e meios que exercitem o controle social formal, caso contrário, se instalará o arbítrio nas resoluções dos conflitos interpessoais, prevalecendo a lei do mais forte na autotutela, em suma, na ausência da disciplina social formal fertiliza-se o campo da vingança privada7.

Importante não esquecer, que a eficácia da disciplina social é a base de legitimação da existência do Estado moderno, vez que na gênese do discurso dos fundamentos de tal Estado está posto, de forma clara, que para superar o estágio da humanidade no qual prevalecia a guerra de todos contra todos, onde o homem era o lobo do homem, necessária a existência de um ente superior que tivesse a prerrogativa de disciplinar a sociedade.

Salutar pois, que neste ponto, para uma melhor compreensão do assunto, elabore-se uma síntese acerca da fundamentação e legitimação do direito de punir: os fundamentos do

\footnotetext{
${ }^{5}$ Sobre o paradigma restaurativo na Justiça do adolescente, Walgrave (2011, tradução livre), para quem: “A justiça restaurativa é um conjunto potencialmente transformador das idéias, potencialmente um paradigma competitivo para criação de novas concepções do sistema de justiça penal, cujo tempo parece nunca chegar: tem gerado uma enorme literatura, incluindo uma séria literatura jurisprudencial. A justiça restaurativa catalisou o início de inúmeros novos programas. Ainda assim, ela permanece as margens do sistema de justiça criminal, lidando principalmente com crimes menores e jovens infratores

${ }^{6}$ Por todos consultar Hobbes (2006).

${ }^{7}$ Sobre o tema, em profundidade, Ferrajoli (2002).
} 
direito de punir repousam na necessidade que a sociedade tem, para sua própria sobrevivência, de ordem social, ou seja, pune-se para que o homem possa viver de forma razoavelmente harmônica em sociedade, mas isso não basta. Há necessidade de que os meios para alcance desse desiderato, as punições - quer sejam penas, quer sejam medidas sócio educativas -, sejam aplicadas de forma legítima.

A legitimação do direito de punir, por seu turno, encontra alicerce, nos fins a que se propõem as punições - intimidação, neutralização, ressocialização, reafirmação do valor da norma, defesa da ordem jurídica - obedecendo a uma série de princípios inerentes à sua existência e aplicação, que ao longo da história foram sendo construídos até alcançarem o status de Princípios Constitucionais de Direito Penal e Processual Penal8.

Desta forma, partindo-se da posição que defende ser necessária, mesmo imprescindível, a atuação do Direito Penal no controle dos atos praticados pelos adolescentes infratores, salutar que sejam delineados os meios para alcance de tal fim e, assim, se deixe claro os rumos que devem ser adotados para elaboração de políticas públicas de controle social formal, devidamente fundamentadas e legitimadas9.

No que pertine ao ente federado responsável pela elaboração e consecução das políticas públicas de segurança afetas ao enfrentamento da crescente prática de atos infracionais no Brasil, ou seja, dentro de uma perspectiva absolutamente formal no âmbito da legitimidade do direito de punir, entendemos que a solução se encontra nos dispositivos legais, ou seja, no devido processo legislativo que determinará tais atribuições.

Dentro de tal perspectiva, pode-se afirmar que o problema não é de ordem formal e sim de ordem material. O Estado está a perder legitimidade em razão da falta de eficiência e, consequentemente, de eficácia no campo do controle social formal.

Entende-se que a multiplicidade de funções atribuídas às penas existentes no Direito Penal brasileiro10, acabam por desvirtuar, senão impedir, a criação e consecução de quaisquer

\footnotetext{
${ }^{8}$ Sobre o tema, Ashworth, (2009, tradução livre), para quem: "O direito penal é por vezes apresentado e discutido como se fosse um sistema de regras. Isso já se tornou evidente, mas não é verdadeiro. Embora existam regras, e embora o Parlamento muitas vezes passe por longos debates antes de promulgar regras, há também uma grande quantidade de discricionariedade que muitas vezes permite que os policiais, procuradores, promotores, juízes e o próprio júri adotem posicionamentos que não se pode dizer terem sido ditados pela lei”. Para maior aprofundamento, Bedê e Senna ( 2009).

${ }^{9}$ Sobre os novos rumos do controle social formal, Guimarães (2013).

${ }^{10}$ Sobre as funções das penas, em profundidade, Guimarães (2007).
} 
políticas públicas na área da segurança comunitária e, portanto, na área do controle social formal.

Como traçar um plano na área das políticas de combate a criminalidade juvenil11 a curto, médio ou longo prazos, sem que se tenha definido, de maneira clara e determinada, qual a finalidade a ser alcançada com a aplicação das medidas socioeducativas?

Concluindo o raciocínio, o alcance da legitimidade no combate aos atos infracionais cometidos por adolescentes, passa, necessariamente, por uma padronização no fim primordial a ser atribuído às medidas socioeducativas.

Ainda que várias das funções das punições possam ser alcançadas, o que chamamos de funções derivadas, uma única função deve servir de norte para que as políticas públicas inerentes à segurança da população possam ser verdadeiramente efetivadas e, assim, reforçar o discurso de fundamentação e legitimação do direito de punir do Estado.

É neste ponto que sobressai o papel dos Municípios brasileiros, vez que entendemos serem, por excelência, os entes federados com maior capacidade para por em prática as medidas delineadas, em razão mesmo de sua maior capacidade de especificidade, por atuarem, dentro das perspectivas da Federação, em um campo micro social, ou seja, em uma perspectiva espacial bem menor que a dos Estados e, obviamente, da Federação .

Em boa hora, pelo menos há indicativos, a Lei 12.594/2012, chamada Lei do SINASE, que instituiu o Sistema Nacional de Atendimento Socioeducativo, parece ter percebido que um padrão mínimo deve ser adotado na finalidade das medidas socioeducativas, assim como, definiu de modo claro o papel dos Municípios em tal desiderato.

Passemos, então, a analisar as propostas contidas nesse novo diploma legal com o objetivo de mensurar a sua adequação aos novos paradigmas de formulação de políticas na área da segurança pública envolvendo os municípios brasileiros.

\section{$3 \mathrm{O}$ fenômeno do ato infracional: demarcações sociojurídicas.}

\footnotetext{
${ }^{11}$ Interessante trabalho sobre o envolvimento de crianças no tráfico de drogas pode ser encontrado em Dowdney (2002).
} 
A Constituição Brasileira de 1988 estabeleceu em seus artigos 227 e 228, a seguir transcritos, as bases para um novo paradigma de tratamento normativo a crianças e adolescentes no Brasil.

Art. 227. É dever da família, da sociedade e do Estado assegurar à criança, ao adolescente e ao jovem, com absoluta prioridade, o direito à vida, à saúde, à alimentação, à educação, ao lazer, à profissionalização, à cultura, à dignidade, ao respeito, à liberdade e à convivência familiar e comunitária, além de colocá-los a salvo de toda forma de negligência, discriminação, exploração, violência, crueldade e opressão. (Redação dada Pela Emenda Constitucional nº 65, de 2010).

(...)

Art. 228. São penalmente inimputáveis os menores de dezoito anos, sujeitos às normas da legislação especial (BRASIL, 2015).

Os referidos dispositivos alinham-se com a normativa internacional que trata do segmento infanto-adolescente, em especial, a Convenção Internacional dos Direitos da Criança, aprovada pela Assembleia Geral da ONU em 1989.

O Estatuto da Criança e do Adolescente, Lei Federal 8.069/90, define o ato infracional como a conduta descrita como crime ou contravenção penal.

A partir desta previsão, o Estatuto estabeleceu uma série de direitos e garantias para os menores de 18 anos acusados de cometerem um ato infracional, os quais estão alinhados com os direitos e garantias já previstos para os adultos, com fundamento na Constituição Federal.

Segundo Paula (2006, p.35)

O Direito da Criança e do Adolescente foi buscar no chamado garantismo penal, concepção indicativa do conjunto de garantias e materiais e processuais que limitam a intervenção do Estado na esfera da liberdade do indivíduo e que projetam uma intervenção estatal estritamente regrada, inspiração para o estabelecimento de seus pilares que, juntados a outros, especiais, determinam a criação de algo novo. Isto não o transforma em Direito Penal, vez eu suas bases são diversas, seus postulados são distintos, sua esfera de incidência outra. (PAULA, 2006, p.35).

Essa delimitação legal foi necessária e representou um avanço na preservação do direito à liberdade de crianças e adolescentes em situação de vulnerabilidade social, uma vez que na vigência do revogado Código de Menores (de 1979) crianças e adolescentes podiam ser privados da liberdade ainda que não tivessem cometido ilícito algum, apenas em razão de se encontrarem na chamada situação irregular, expressão cunhada para designar uma variedade de situações envolvidas no contexto dos chamados "menores", conforme transcrição do artigo $2^{\circ}$ da lei revogada: 
Art. $2^{\circ}$ Para os efeitos deste Código, considera-se em situação irregular o menor: I - privado de condições essenciais à sua subsistência, saúde e instrução obrigatória, ainda que eventualmente, em razão de:

a) falta, ação ou omissão dos pais ou responsável;

b) manifesta impossibilidade dos pais ou responsável para provê-las;

Il - vítima de maus tratos ou castigos imoderados impostos pelos pais ou responsável;

III - em perigo moral, devido a:

a) encontrar-se, de modo habitual, em ambiente contrário aos bons costumes;

b) exploração em atividade contrária aos bons costumes;

IV - privado de representação ou assistência legal, pela falta eventual dos pais ou responsável;

V - Com desvio de conduta, em virtude de grave inadaptação familiar ou comunitária;

VI - autor de infração penal. (BRASIL, 2016, grifo nosso).

Vale ressaltar que a categoria "menor", nesse contexto, não tinha apenas uma dimensão técnica, designativa da pessoa com menoridade civil, assumindo uma dimensão política, pois retirava de crianças e adolescentes vulnerabilizados socialmente, a condição de sujeitos, tratando-os apenas como objeto de intervenção. O sentido político do termo "menor” residiria também em torno de sua associação apenas às crianças e adolescentes que estavam em situação de pobreza, vítimas de maus-tratos ou que tivessem praticado alguma conduta ilícita. Essa era a perspectiva da chamada doutrina da situação irregular: enquadrar todo o segmento da infância e adolescência que estivesse em situação de violação de direitos como menores, estabelecendo uma distinção entre estes e a parcela do segmento infanto-juvenil que estava em pleno gozo dos direitos.

A reflexão de Silva (2006, p. 51), nos ajuda a compreender como atuava o Estado na vigência da doutrina da situação irregular:

No Brasil, por exemplo, existia uma Delegacia de Polícia de "Proteção ao Menor", onde meninos pobres eram encarcerados "para serem diagnosticados e tratados”.

A "situação irregular" abrangia do abandono e vitimização do "menor" aos "atos anti-sociais” por ele praticados.

A “tutela” e os bons propósitos do superior interesse do "menor" não permitiam falar em delinquência juvenil.

Não se admitia que o "menor” fosse estigmatizado pela sentença penal. Exorcizavase o juízo criminal pelos aspectos "retributivo" e "punitivo”, mas "encaminhavamse” crianças e adolescentes a celas iguais às da pior carceragem, sem garantir um dos mais elementares direitos da pessoa humana, o devido processo legal. (SILVA, 2006, p. 51).

Com a abertura democrática, após a ditadura militar, e instalação do processo constituinte para elaboração de uma nova Constituição Brasileira, o chamado movimento da infância se mobilizou para inclusão no texto constitucional de artigos que viessem a introduzir 
no ordenamento jurídico brasileiro a chamada Doutrina da Proteção Integral, pautada na concepção de crianças e adolescentes como sujeitos de direitos, pessoas em condição peculiar de desenvolvimento e prioridade absoluta. Durante a Constituinte, assegurou-se no texto constitucional, no artigo 228, a imputabilidade penal somente a partir dos 18 anos, direito individual de todas as crianças e adolescentes brasileiros.

\section{O segmento adolescente no cenário da violência}

Feitas as demarcações legais, cabe uma abordagem acerca do contexto social em que ocorre o ato infracional, em geral marcado por múltiplas ordens de violência com destaque para a violência estrutural e física ${ }^{12}$.

Segundo o estudo Mapa da Violência 2015, as taxas de homicídio por arma de fogo no Brasil da chamada população jovem (de 15 a 29 anos de idade) é superior à da população não jovem, chegando algumas unidades da Federação a apresentar o índice de quatro mortes de jovens para cada uma morte de não jovem (WAISELFISZ, 2015).

No tocante ao perfil da população vitimada por armas de fogo no Brasil, o mesmo estudo aponta que 96\% é constituído de pessoas do sexo masculino e 142\% de pessoas negras, ou seja, conforme o estudo é quase duas vezes e meio maior o número de mortes de pessoas negras em relação às brancas.

Uma primeira demarcação a se fazer quanto ao fenômeno do ato infracional, é que este ocorre em meio a um cenário de violência física, que afeta sobretudo os jovens negros.

Por outro lado, quando se analisa as estatísticas dos atos infracionais, observa-se que a maior parte das condutas ilícitas praticadas por adolescentes enquadram-se na categoria dos chamados crimes contra o patrimônio, e não de crimes contra a vida. De acordo com levantamentos do Fórum Brasileiro de Segurança Pública, dos “20.532 jovens cumprindo medidas socioeducativas no Brasil em 2012, apenas 11,1\% correspondem a crimes violentos contra à vida (homicídios e latrocínios)” (FORUM, 2014, p.6).

\footnotetext{
${ }^{12}$ Sobre o tema "Juventude, drogas, álcool e crime”, especificamente, Newburn (2007, p. 592, tradução nossa), para quem: "A pesquisa também sugeriu que os índices de uso de drogas, como crack e heroína, são significativamente mais elevados entre os menores infratores que cometem infrações graves e/ou frequentes do que na população em geral, mostrando, também, uma relação clara entre o tipo e a freqüência do uso de drogas e o tipo e frequência de infrações cometidas”.
} 
Acerca do assunto, o Instituto de Pesquisas Econômicas Aplicadas (IPEA) produziu uma nota técnica em que compilou uma série de informações sobre o fenômeno do ato infracional, no intuito de subsidiar o debate sobre as propostas de emendas à Constituição Federal que visam reduzir a maioridade penal ${ }^{13}$. No referido documento, consta que no ano de 2013, era de 21,1 milhões a população brasileira adolescente, com idade de 12 a 18 anos incompletos, sendo que apenas 23,1 mil adolescentes estavam internados ${ }^{14}$.

O mesmo documento reitera a informação de que a maioria dos delitos praticados refere-se a crimes contra o patrimônio, o que levou Oliveira (2015, p. 26) a traçar o seguinte informe estatístico:

[...] as infrações patrimoniais como furto, roubo e envolvimento com o tráfico de drogas constituíram-se nos principais delitos praticados pelos adolescentes em cumprimento de medida socioeducativa de privação de liberdade no Brasil nos últimos três anos. Em 2011, roubo (38,12\%), furto (5,6\%) e tráfico (26,56\%) representaram, juntos, mais de $70 \%$ do total de delitos praticados pelos adolescentes detidos. Em 2012, esses atos infracionais alcançaram, aproximadamente, 70\% do total e, em 2013, cerca de 67\%. Por sua vez, os delitos considerados graves, como homicídios (8,39\%), latrocínio (1,95\%), lesão corporal $(1,3 \%)$ e estupro $(1,05 \%)$ alcançaram, em 2011, 11,7\% do total dos atos praticados pelos adolescentes detidos no Brasil. Em 2012, tais infrações representaram 13,5\% e, em 2013, 12,7\%. (OLIVEIRA, 2015, p. 26).

Estas estatísticas nos obrigam a refletir sobre o perfil dos adolescentes que cometem atos infracionais bem como os fatores que os levam a praticar tais atos infracionais.

Os números apontam que grande parte dos adolescentes infratores são negros, pertencem a famílias de baixa renda e têm acentuada defasagem escolar, revelando assim, que os autores de ato infracional no Brasil, são os herdeiros da ação e omissão estatal perpetrada ao longo de décadas, que alijou a população negra brasileira do pleno acesso às políticas públicas.

\footnotetext{
${ }^{13}$ Especificamente, sobre o tema, Crisóstomo (2001).

${ }^{14}$ Sempre pertinente a observação de Lemgruber (2002), acerca do controle da criminalidade: “A temática da criminalidade e dos meios de controla-la carrega, por sua própria natureza, um forte apelo emocional. Facilmente o medo se converte em caldo de cultura para demandas vingativas e autoritárias, sobretudo quando amplificado pela mídia e manipulado por interesses políticos. No Brasil, onde os problemas de segurança vêm ganhando dimensões epidêmicas, são poucas, ainda, as pessoas e instituições dedicadas a estuda-los seriamente, assim como são muito precários os dados disponíveis para fundamentar diagnósticos precisos e políticas eficazes de redução da violência e do crime. A escassez de informações, não só sobre o que ocorre no próprio país mas também sobre experiências internacionais, deixa espaço para a reprodução de crenças e mitos que há muito já vêm sendo questionados em outras partes do mundo - como a eficácia da pena de morte, os benefícios do endurecimento penal, as vantagens da privatizações de presídios de prisões e os efeitos dissuasivos da pena privativa de liberdade."
} 
Diante dessas constatações, a compreensão do fenômeno do ato infracional impõe uma reflexão acerca do contexto social, do modelo de sociedade em que estes jovens estão inseridos, assim como da fase de desenvolvimento em que se encontram, qual seja: a adolescência.

Assim, por um lado, os adolescentes vivem em uma sociedade capitalista, com forte apelo consumista, na qual o valor das pessoas é dimensionado em razão do que elas possuem ou ostentam possuir e, por outro, encontram-se em uma fase da vida marcada por intensas transformações biopsíquicas.

Nesse contexto, a análise do ato infracional praticado por um adolescente não deve se resumir a uma operação de confronto do fato com a prescrição legal, ou seja, um exercício de mera objetivação, deve, sobretudo, considerar a história de vida do autor da infração. De acordo com Teixeira (2006, p. 427) a abordagem do ato infracional implica analisar:

[...] as variáveis relativas às intensas mudanças físicas, biológicas, psicológicas; variáveis relativas a seus grupos de pertencimento, a seu meio social e a seu trânsito no mundo da cultura, nestes tempos de ausência de fronteiras geográficas e novas tecnologias de informação que vão construindo outros padrões de sociabilidade. (TEIXEIRA, 2006, p. 427).

Segundo a referida a autora, a "biografia pessoal se organiza a partir de inúmeros acontecimentos, vivências objetivas e subjetivas, e o delito é um dos acontecimentos na vida do adolescente" (TEIXEIRA,2006, p. 427).

Assim, o apelo para o consumo, característica da era em que vivemos, embora seja um fenômeno que perpassa todas as classes sociais, produz efeitos nefastos junto aos jovens de baixa renda, dada a impossibilidade de acesso aos bens desejados pela carência de recursos financeiros. Por outro lado, a sociedade do consumo caracteriza-se pela constante produção de necessidades, às quais são efêmeras à medida que constantemente se produzem novos objetos de desejo ${ }^{15}$.

\footnotetext{
${ }^{15}$ Tal fenômeno foi também estudado e, a nosso ver, aperfeiçoado por Merton (2009, p. 167, tradução nossa), que assim se posiciona acerca do tema: "Não obstante a nossa persistente ideologia de "mobilidade de classes", o avanço em direção à meta do sucesso é relativamente raro e notadamente difícil para aqueles com pouca instrução, pouca educação formal e poucos recursos econômicos. A pressão dominante segue em direção a uma atenuação gradual dos esforços legítimos, para um aumento do uso de esforços ilegítimos, porém, que se configuram como meios mais ou menos eficazes para alcance das metas impostas. Para aqueles localizados nos estratos inferiores da estrutura social, os meios culturais tornam-se exigências incompatíveis. Por um lado, eles são convidados a orientar suas condutas com a perspectiva de riqueza (prosperidade) - "todo homem é um rei", disse Marden e Carnegie e Long - e por outro lado, são-lhes negados os meios institucionais para alcançá-los. A consequência desse desequilíbrio estrutural é alta taxa de comportamentos desviantes”.
} 
Outro fator que contribuiu para que a maioria dos atos infracionais praticados sejam crimes contra o patrimônio, reside no envolvimento dos adolescentes com o consumo de drogas, situação que os leva a buscarem meios de angariar recursos para a compra de drogas.

\section{Medidas de responsabilização e o papel do município diante do ato infracional.}

Para os adolescentes que cometem ato infracional, o Estatuto da Criança e do Adolescente prevê uma série de medidas a serem aplicadas, as quais se subdividem em medidas protetivas e medidas socioeducativas. De maneira sintética, pode-se afirmar que as primeiras visam restabelecer direitos enquanto as medidas socioeducativas tem cunho educativo e sancionatório, uma vez que incluem desde uma advertência até a restrição da liberdade, através da Internação. A seguir o artigo da lei que estabelece as referidas medidas:

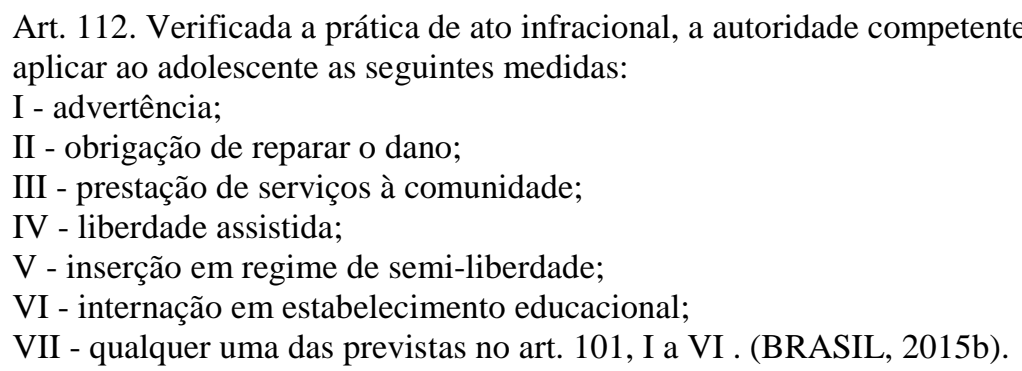

As medidas socioeducativas podem ser agrupadas em duas categorias: medidas em meio aberto e medidas privativas da liberdade.

Os critérios para definição das medidas socioeducativas mais adequadas a serem aplicadas são: a capacidade do adolescente em cumprir a medida; as circunstâncias e a gravidade da infração praticada, conforme dispõe o parágrafo primeiro do art. 112.

Esta previsão legal denota que as medidas socioeducativas tem um cunho sancionatório, pois quanto mais grave o ato infracional mais dura será a medida a ser imposta, todavia, sem perder de vista sua natureza educativa, uma vez que os adolescentes encontramse em condição peculiar de desenvolvimento.

Ressalte-se, todavia, que é controverso o entendimento acerca da natureza jurídica das medidas socioeducativas, dado a concepção de que estas não teriam natureza sancionatória, mas somente socioeducativa. 


\subsection{Alcances da Lei 12.594/2012: a instituição do SINASE.}

A Lei 12.594/2012, chamada Lei do SINASE, que instituiu o Sistema Nacional de Atendimento Socioeducativo, foi concebida em atendimento às demandas da sociedade civil organizada e instituições que atuavam na execução das medidas socioeducativas, as quais buscavam uma regulamentação do processo de execução destas medidas, a fim de coibir condutas discricionárias por parte dos chamados operadores do Direito em face da lacuna legislativa quanto à temática.

Cabe aqui uma incursão pelo processo de elaboração da referida lei, iniciado ainda no ano de 2002, com a realização de encontros que contaram com participação de diversos atores representantes das instâncias que integram o chamado Sistema de Garantia dos Direitos de Crianças e Adolescentes, os quais objetivaram discutir uma proposta de Lei de Execução de Medidas Socioeducativas elaborada pela Associação Brasileira de Magistrados e Promotores da Infância e Juventude- ABMP. Estes eventos tiveram como resultado, a constituição de dois grupos de trabalho “com tarefas específicas embora complementares, a saber: a elaboração de um projeto de lei de execução de medidas socioeducativas e a elaboração de um documento teórico-operacional para execução dessas medidas” (BRASIL, 2006, p.16).

O documento base do SINASE, de cunho teórico-operacional, foi aprovado em 2006 pelo CONANDA através da Resolução n¹19/2006 e a lei que trata da execução das medidas em 2012.

Uma das novidades desta lei foi a delimitação dos objetivos das medidas socioeducativas, conforme previsto no artigo art. $1^{\circ}, \S 2^{\circ}$, transcrito a seguir:

$\S 20$ Entendem-se por medidas socioeducativas as previstas no art. 112 da Lei no 8.069, de 13 de julho de 1990 (Estatuto da Criança e do Adolescente), as quais têm por objetivos:

I- a responsabilização do adolescente quanto às consequências lesivas do ato infracional, sempre que possível incentivando a sua reparação;

II - a integração social do adolescente e a garantia de seus direitos individuais e sociais, por meio do cumprimento de seu plano individual de atendimento; e III - a desaprovação da conduta infracional, efetivando as disposições da sentença como parâmetro máximo de privação de liberdade ou restrição de direitos, observados os limites previstos em lei. (BRASIL, 2017, grifo nosso). 
Como se observa a Lei do SINASE deixa claro que as medidas socioeducativas visam responsabilizar o adolescente pela conduta ilícita, assim como desaprovar a conduta infracional. Em relação ao terceiro objetivo da lei, parece que o legislador quis romper de modo explícito com uma ideia que se propagou em torno do Estatuto da Criança e do Adolescente de que este visaria somente proteger o adolescente, sendo tal lei utilizada para “passar a mão na cabeça” dos autores de ato infracional.

Cabe ressaltar que o Estatuto da Criança e do Adolescente, ao dispor sobre a possibilidade do adolescente responder pela prática do ato infracional através de uma medida socioeducativa em meio aberto (prestação de serviços à comunidade ou liberdade assistida), tornou-se a primeira referência no ordenamento jurídico brasileiro para o estabelecimento das chamadas penas alternativas, que posteriormente seriam instituídas para os adultos, através da Lei 9.099/95.

No tocante às medidas que implicam privação da liberdade (semiliberdade e internação) estas sujeitam-se aos princípios da brevidade e excepcionalidade, ou seja, estas são as últimas das medidas a serem aplicadas e ainda somente pelo tempo mínimo necessário. Isto porque, entende-se que os adolescentes estão em fase de desenvolvimento e, portanto, devem responder de maneira diferenciada dos adultos pelos ilícitos que vierem a praticar.

\subsection{A atuação do município diante do ato infracional.}

A partir da Constituição Federal de 1988 e do Estatuto da Criança e do Adolescente, o município assume papel decisivo na implementação das políticas públicas voltadas para crianças e adolescentes, tendo em vista a diretriz constitucional da descentralização políticoadministrativa, prevista no art. 204, inc. I da nossa Carta Magna assim como a disposição contida no art. 88, inc. I do ECA que aponta a municipalização do atendimento como diretriz primeira da Política de Atendimento dos Direitos da Criança e do Adolescente.

A opção pela municipalização do atendimento no âmbito do sistema socioeducativo é política e estratégica, pois implica o necessário envolvimento da sociedade local no enfrentamento da problemática do ato infracional, devendo o adolescente em conflito com a lei ser atendido inicialmente e cumprir a medida socioeducativa nos limites geográficos do município de sua residência, possibilitando assim o protagonismo da família e da comunidade no processo de reinserção social do adolescente autor de ato infracional. 
Nesse sentido, o documento base que organiza o SINASE trouxe uma importante ressalva quando ao teor da municipalização no campo do Direito da Criança, conforme excerto:

[...] a municipalização do atendimento é um mandamento de referência para as práticas de atendimento, exigindo que sejam prestadas dentro ou próximas dos limites geográficos dos municípios. Portanto, a municipalização do atendimento preconizada pelo ECA não tem a mesma acepção do conceito de municipalização adotado pela doutrina do Direito Administrativo, que o assume como uma modalidade de descentralização política ou administrativa.

A municipalização do atendimento tem conteúdo programático, sendo uma orientação para os atores na área da infância e da adolescência, funcionando como objetivo a ser perseguido e rea lizado sempre que houver recursos materiais para tanto e não se configurarem conflitos com outros princípios da doutrina da Proteção Integral, considerados de maior relevância no caso concreto (BRASIL 2006, p.30, grifo nosso).

$\mathrm{Na}$ seara das medidas socioeducativas, coube aos municípios a execução das chamadas medidas em meio aberto que necessitam da intermediação de uma entidade de atendimento, quais sejam: prestação de serviços à comunidade e liberdade assistida.

Nos termos do Estatuto da Criança e do Adolescente, a prestação de serviços comunitários consiste na realização de tarefas gratuitas de interesse geral, por período não excedente a seis meses, junto a entidades assistenciais, hospitais, escolas e outros estabelecimentos congêneres, bem como em programas comunitários ou governamentais; já a liberdade assistida implica em acompanhamento, auxílio e orientação do adolescente que cometeu ato infracional, por um período mínimo de seis meses, devendo este frequentar escola, participar de cursos profissionalizantes e outras atividades que possam contribuir para sua "promoção social”, de modo a prevenir a reiteração na prática do ato infracional.

Esta competência municipal, no âmbito do SINASE, foi estabelecida no artigo $5^{\circ}$ da Lei 12.594/2012, transcrito a seguir:

Art. 5o Compete aos Municípios:

I - formular, instituir, coordenar e manter o Sistema Municipal de Atendimento Socioeducativo, respeitadas as diretrizes fixadas pela União e pelo respectivo Estado;

II - elaborar o Plano Municipal de Atendimento Socioeducativo, em conformidade com o Plano Nacional e o respectivo Plano Estadual;

III - criar e manter programas de atendimento para a execução das medidas socioeducativas em meio aberto;

IV - editar normas complementares para a organização e funcionamento dos programas do seu Sistema de Atendimento Socioeducativo;

V - cadastrar-se no Sistema Nacional de Informações sobre o Atendimento Socioeducativo e fornecer regularmente os dados necessários ao povoamento e à atualização do Sistema; e 
VI - cofinanciar, conjuntamente com os demais entes federados, a execução de programas e ações destinados ao atendimento inicial de adolescente apreendido para apuração de ato infracional, bem como aqueles destinados a adolescente a quem foi aplicada medida socioeducativa em meio aberto. ( BRASIL, 2017, grifo nosso).

A lei do SINASE também reiterou expressamente disposição contida na Lei 8.069/90 de que os programas de atendimento devem inscrever-se no Conselho Municipal dos Direitos da Criança e do Adolescente, instância responsável por verificar se Programa atende aos requisitos para funcionamento das entidades de atendimento estabelecidos no ECA.

Considerando a necessária interface existente entre a política de atendimento dos direitos da criança e a política de assistência social, no tocante ao atendimento de crianças em situação de risco e/ou vulnerabilidade social, atualmente o atendimento de adolescentes que praticaram ato infracional sentenciados a cumprirem medidas em meio aberto é realizado prioritariamente pelos Centros de Referência Especializados em Assistência Social - CREAS.

\section{CONCLUSÃO}

De tudo quanto exposto no trabalho que hora se encerra, a primeira e mais importante conclusão a ser apresentada é a que reforça o entendimento da legitimidade do Estado e, por via de consequência, dos seus órgãos responsáveis, em sua atuação no controle social formal.

Infere-se, outrossim, de forma indicativa, que há uma premente necessidade na organização, pela via do planejamento, nas políticas públicas a serem elaboradas no âmbito do controle social formal, nas quais os órgãos envolvidos, assim como, os objetivos a serem alcançados devem estar traçados de forma clara e objetiva.

Como pressuposto da conclusão acima delineada, necessário que se padronize a função atribuída às punições, vez que com tantas funções atribuídas às penas, é tarefa impossível planejar e organizar políticas na área da segurança pública, ou seja, deve-se separar de modo claro a função principal a ser perseguida pelas punições das funções derivadas que podem decorrer das mesmas.

Em uma perspectiva legal, deduz-se que a legislação acerca dos menores infratores, no que pertine à delimitação do ato infracional, assim como de sua responsabilização, é suficiente e representa um grande avanço em relação ao revogado Código de Menores. 
No Brasil, o perfil dos autores de ato infratores está estreitamente ligado à condição socioeconômica dos mesmos, ou seja, os números apontam que grande parte dos adolescentes infratores são negros, pertencem a famílias de baixa renda e têm acentuada defasagem escolar, estando entre as principais vítimas da ação e omissão estatal perpetrada ao longo de décadas, que alijou a população negra brasileira do pleno acesso às políticas públicas.

Chama-se a atenção para a pertinência de integração dos Municípios brasileiros na área do controle social formal, vez que entendemos serem, por excelência, os entes federados com maior capacidade para por em prática as medidas delineadas em tal órbita, em razão mesmo de sua maior capacidade de especificidade, por atuarem, dentro das perspectivas da Federação, em um campo micro social, ou seja, em uma perspectiva espacial bem menor que a dos Estados e, obviamente, da Federação .

Por fim, enaltece-se a percepção do legislador, que passo a passo tem se vertido para a integração dos Municípios brasileiros na área de planejamento e execução de políticas voltadas para o segmento da segurança pública, sendo a Lei 12.594/2012, conhecida como Lei do SINASE, um claro indicativo de tal posição.

\section{REFERÊNCIAS}

ANDRADE, Vera Regina Pereira de. Por que a Criminologia (e qual a Criminologia) é importante no ensino jurídico?. 18 mar. de 2008. Disponível em: www.cartaforense.com.br/Materia.aspx?id=1168. Acesso em 15 fev. de 2012.

ASHWORTH, Andrew. Principles of Criminal Law. 6 edition. London: Oxford University Press, 2009, 536 p.

BEDÊ Jr., Américo; SENNA, Gustavo. Princípios do Processo Penal: entre o garantismo e a efetividade da sanção. São Paulo: Editora Revista dos Tribunais, 2009.

BRASIL. Sistema Nacional De Atendimento Socioeducativo - SINASE/Secretaria Especial dos Direitos Humanos. Brasília-DF: CONANDA, 2006. 
BRASIL. Constituição da República Federativa do Brasil de 1988. http://www.planalto.gov.br/ccivil_03/constituicao/constituicaocompilado.htm. Acesso em 10 de junho de 2015.

BRASIL. Estatuto da Criança e do Adolescente. Lei Federal 8.069/90. http://www.planalto.gov.br/CCIVIL_03/leis/L8069.htm. Acesso em 10 de junho de 2015b.

BRASIL. Decreto $\mathrm{n}^{0}$ 17.943-A, de 12 de outubro de 1927. Disponível em http://www2.camara.leg.br/legin/fed/decret/1920-1929/decreto-17943-a-12-outubro-1927501820-publicacaooriginal-1-pe.html. Acesso em 12 de março de 2016.

BRASIL. Lei $\mathbf{n}^{\mathbf{0}} \mathbf{1 2 . 5 9 4}$ de 18 de janeiro de 2012. Disponível em http://www.planalto.gov.br/ccivil_03/_ato2011-2014/2012/lei/l12594.htm. Acesso em 18 de dezembro de 2017.

CARRANZA, Elias. Delito y seguridad de los habitantes. Madrid: Siglo XXI, 1997.

CRISÓSTOMO, Eliana Cristina R. Taveira. (Org.) A razão da Idade: mitos e verdades. Brasília: MJ/SEDH/DCA, 2001

DOWDNEY, Luke. De aviãozinho a soldados: o crescente envolvimento de crianças e adolescentes nas lutas de grupos armados do tráfico de drogas no Rio de Janeiro. In: OLIVEIRA, Nilson Vieira. Insegurança Pública. Reflexões sobre a criminalidade e a violência urbana. São Paulo: Nova Alexandria, 2002.

FERRAJOLI, Luigi. Direito e Razão. Teoria do Garantismo Penal. Tradução de Ana Paula Zomer et al. São Paulo: RT, 2002.

FÓRUM Brasileiro de Segurança Pública. Anuário Brasileiro de Segurança Pública 2014, São Paulo: 2014.

GUIMARÃES, Claudio Alberto Gabriel. Funções da pena privativa de liberdade no sistema penal capitalista. 2 ed. Rio de Janeiro: Revan, 2007, 350p. 
Constituição, Ministério Público e Direito Penal. A defesa do Estado

Democrático no âmbito Punitivo. Rio de Janeiro: Revan, 2010, 286p.

Reflexões acerca do controle social formal: rediscutindo os

fundamentos do direito de punir. Jun. de 2013. Disponível em: http://www.epublicacoes.uerj.br/index.php/rfduerj/article/view/4894. acesso 18 dez. de 2013. Revista da Faculdade de Direito da UERJ. Rio de Janeiro, v.1, n.23

; PEREIRA Paulo. Reflexões a respeito da necessidade de participação dos Municípios na formulação e na implementação de políticas de segurança pública. Revista Quaestio Juris. Rio de Janeiro, v. 7, n. 02, p. 812-839, 2014.

HULSMAN, Louk et al. Abolicionismo penal. Traducción por Mariano Alberto Ciafardini y Mirta Lilián Bondanza. Buenos Aires: Ediar, 1989.

; CELIS, Jacqueline Bernat de. Penas Perdidas: o sistema penal em questão. Tradução de Maria Lúcia Karam. 2. ed. Niterói-RJ: Luam, 1997.

HOBBES, Thomas. Leviatã ou matéria, forma e poder de um Estado eclesiástico e civil. Tradução de Alex Marins. São Paulo: Martin Claret, 2006, 519 p.

LEMGRUBER, Julita. Controle da criminalidade: mitos e fatos In: OLIVEIRA, Nilson Vieira. Insegurança Pública. Reflexões sobre a criminalidade e a violência urbana. São Paulo: Nova Alexandria, 2002.

LEWIS, C. S, The humanitarian theory of punishment. In: TONRY, Michael. Why Punish? How much? A reader on punishment. Oxford: Oxford University Press, 2011.

MERTON, Robert K. Social structure and anomie. In: NEWBURN, Tim. (Org.) Key readings in criminology. London: Willan Publishing, 2009, p. 165-168.

MUÑOZ CONDE, Francisco. Direito penal e controle social. Tradução de Cintia Toledo Miranda Chaves. Rio de Janeiro: Forense, 2005.

Revista de Direito Penal, Processo Penal e Constituição | e-ISSN: 2526-0200 | Maranhão | v. 3 | n. 2 | p. 161 - 180 | Jul/Dez. 2017. 
NEWBURN, Tim. Youth crime and youth culture. The Oxford Handbook of Criminology. Oxford: Oxford Univirsity Press, 2007.

OLIVEIRA, Raissa Menezes de e SILVA, Enid Rocha Andrade da. Nota técnica $\mathbf{n}^{\mathbf{0}} \mathbf{2 0}$. $\mathbf{O}$ Adolescente em Conflito com a Lei e o Debate sobre a Redução da Maioridade Penal: esclarecimentos necessários, Brasília: IPEA, 2015.

PAULA, Paulo Afonso Garrido de. Natuteza do sistema de responsabilização do adolescente autor de ato infracional in: JUSTIÇA, ADOLESCENTE E ATO INFRACIONAL: socioeducação e responsabilidação, São Paulo: ILANUD, 2006.

SILVA, Antonio Fernando do Amaral e. O Estatuto da Criança e do Adolescente e Sistema de Responsabilidade Penal Juvenil ou o mito da Inimputabilidade Penal in: JUSTIÇA, ADOLESCENTE E ATO INFRACIONAL: socioeducação e responsabilidação, São Paulo: ILANUD, 2006.

TEIXEIRA, Maria de Lourdes Trassi. Evitar o desperdício de vidas in: JUSTIÇA, ADOLESCENTE E ATO INFRACIONAL: socioeducação e responsabilidação, São Paulo: ILANUD, 2006.

WALGRAVE, Lode. Restauration in youth justice. In: TONRY, Michael. Why Punish? How much? A reader on punishment. Oxford: Oxford University Press, 2011.

WAISELFISZ, Julio Jacobo. Mapa da Violência: mortes matadas por arma de fogo, Brasília: UNESCO, 2015. 